\title{
The use of lorcaserin in the management of obesity: a critical appraisal
}

This article was published in the following Dove Press journal:

Drug Design, Development and Therapy

20 December 2010

Number of times this article has been viewed

Bo Bai

Yu Wang

Department of Pharmacology and Pharmacy, Li Ka Shing Faculty of Medicine, University of Hong Kong, Hong Kong, People's Republic of China

Correspondence: Yu Wang

Department of Pharmacology and Pharmacy, University of Hong Kong,

Faculty of Medicine Building,

2I Sassoon Rd, Pokfulam,

Hong Kong, People's Republic of China

Tel +86 85228192864

Fax +86852 28I70859

Email yuwanghk@hku.hk
Abstract: Obesity is a chronic disease with a high prevalence in both developed and developing countries. Effective management of this worldwide epidemic will have a significant impact on the health care system globally. Lifestyle interventions, such as restricting calorie consumption and increasing physical activity, remain a major component of weight-reduction programs. The development of pharmacotherapy for the management of obesity is still at the infancy stage. Side effects have been the key issue for anti-obesity drugs previously withdrawn from the market. The focus of this review, lorcaserin, is a selective serotonin receptor agonist that is currently undergoing Phase III evaluations. The efficacy of this drug in reducing body weight and improving metabolic parameters of obese patients has been demonstrated in two recent clinical trials. The available evidence indicates that this drug does not show unwanted effects on heart valves or pulmonary artery pressure, and the treatment improves the risk factors for type 2 diabetes and cardiovascular diseases. Despite these promising results, additional experimental and clinical studies are critical for the approval of lorcaserin as a new anti-obesity monodrug therapy by the US Food and Drug Administration.

Keywords: obesity, anti-obesity drug, 5-hydroxytryptamine receptor agonist, clinical trial

\section{Introduction: pharmacotherapy for obesity management}

Obesity, a chronic pathological condition of abnormal or excessive fat accumulation in the body, has become a worldwide pandemic. The most commonly adopted method to measure obesity is by calculating body mass index (BMI), defined as a person's weight in kilograms divided by the square of their height in meters. Individuals with a BMI equal to or more than 30 are classified as obese, whereas those with a BMI between 25 and 29.9 are classified as overweight. ${ }^{1}$ Obesity has received considerable attention as a major public health hazard. It is most prevalent in Western societies, but a rapid increase is also seen in the developing world. ${ }^{2}$ The latest World Health Organization projections have indicated that whereas in 2005 at least 1 in 3 of the world's adult population was overweight and almost 1 in 10 was obese, by 2015 approximately 2.3 billion adults will be overweight and more than 700 million will be obese. Importantly, the alarming increase in the prevalence of obesity has also been observed in children. The worldwide prevalence of childhood overweight and obesity increased from $4.2 \%$ in 1990 to $6.7 \%$ in 2010 . This trend is expected to reach $9.1 \%$, or approximately 60 million, in $2020 .{ }^{3}$

Overweight and obesity are major risk factors for a wide range of serious health consequences, including cardiovascular diseases (heart failure and stroke), diabetes, 
dyslipidemia, obstructive sleep apnea, asthma, musculoskeletal disorders, and cancers. ${ }^{4}$ Obesity has become a leading cause of preventable death, second only to tobacco. ${ }^{5}$ Current strategies for controlling body weight include diet, exercise, drug therapy, bariatric surgery, or combinations of the above. ${ }^{6}$ The fundamental principle for weight management is to reduce energy intake and/or increase expenditure. Lifestyle changes and regular exercise facilitate weight loss and improve metabolic, cardiac, and vascular functions in obese patients. ${ }^{7}$ For example, modest weight loss of as little as 5\% results in a significant reduction in incidence of type 2 diabetes. ${ }^{8}$ The blood pressure reduction achieved by adequate weight loss is equivalent to that obtained by using low-dose pharmacological therapy. ${ }^{9}$ Weight loss has also been shown to improve liver function in patients with nonalcoholic fatty liver disease. ${ }^{10,11}$ Unfortunately, failure to maintain changes in diet and exercise patterns is a major reason for weight regain experienced in most people. Bariatric surgery, generally used for patients with morbid obesity (BMI equal to or more than 40), is effective for sustaining weight loss but often causes complications. ${ }^{12,13}$ Pharmacotherapy, combined with lifestyle intervention, has demonstrated efficacy in weight loss. ${ }^{14}$ The general guidelines recommend drug therapy for obesity when the BMI is equal to or more than 30 or when the BMI is between 27.0 and 29.9 with a major obesity-related comorbidity (eg, hypertension, diabetes, and obstructive sleep apnea). Despite these strategies, obesity and its associated health complications remain widely prevalent, and effective treatment is desperately needed to target specific physiologic pathways.
There are several anti-obesity drugs on the market for short-term usage. Currently, only one drug is approved by the US Food and Drug Administration (FDA) for long-term maintenance of weight loss (Table 1). ${ }^{15}$ Orlistat (Xenical [Roche Laboratories, Nutley, NJ, USA] and over-the-counter Alli [GlaxoSmithKline, Philadelphia, PA, USA]) blocks caloric absorption of the ingested fat by inhibiting gastric and pancreatic lipases in the gut lumen. ${ }^{16}$ The inactivated enzymes cannot hydrolyze dietary fat in the form of triglycerides into absorbable free fatty acids and monoglycerides, which may have a positive effect on weight control. Orlistat is prescribed for obese patients with a BMI of 30 or more. Additionally, patients with a BMI of 27 or higher and who have other risk factors, including hypertension, diabetes, and dyslipidemia, are indicated to take this drug combined with a reduced-calorie diet. The systemic adverse effects of orlistat are rare. It is available at half the dose as an over-the-counter preparation. Orlistat can reduce the absorption of fat-soluble vitamins and beta-carotene. Thus, vitamin supplementation is recommended. ${ }^{16}$ An efficacy in inducing weight loss of up to $8 \%-10 \%$ has been demonstrated for orlistat. ${ }^{17}$ However, patients often regain weight upon discontinuation of the medication, and there are no long-term safety or efficacy data available for using this drug beyond 2 years.

This review focuses on a centrally acting drug, lorcaserin, which is an anorectic weight-loss agent acting as a selective serotonin receptor $2 \mathrm{C}$ agonist and currently undergoing Phase III clinical trials. ${ }^{18}$ In particular, its pharmacology (including action mechanisms, pharmacokinetics, efficacy, and drug safety) and patient-focused perspectives (such as quality of life, satisfaction, acceptability, adherence, and uptake) will be discussed.

Table I Drugs approved by the US Food and Drug Administration for obesity treatment

\begin{tabular}{|c|c|c|c|}
\hline Generic name & Mechanism of action & Usage & Common side effects \\
\hline Orlistat & Lipase inhibitor & $\begin{array}{l}\text { Long-term treatment } \\
\text { (up to } 12 \text { months) for } \\
\text { adults and children } \\
\text { age } 12 \text { years and older }\end{array}$ & $\begin{array}{l}\text { Gastrointestinal symptoms (cramping, diarrhea, oily } \\
\text { spotting), reduced absorption of fat-soluble vitamins }\end{array}$ \\
\hline Diethylpropion & Appetite suppressant & $\begin{array}{l}\text { Short-term treatment } \\
\text { (up to } 12 \text { weeks) for adults }\end{array}$ & $\begin{array}{l}\text { Precordial pain, elevation of blood pressure, } \\
\text { blurred vision, dizziness, anxiety, depression, } \\
\text { abdominal discomfort }\end{array}$ \\
\hline Phentermine & Appetite suppressant & $\begin{array}{l}\text { Short-term treatment } \\
\text { (up to } 12 \text { weeks) for adults }\end{array}$ & $\begin{array}{l}\text { Primary pulmonary hypertension and/or regurgitant } \\
\text { cardiac valvular disease, dry mouth, unpleasant taste, } \\
\text { diarrhea, constipation, vomiting, headache, insomnia, } \\
\text { shortness of breath, chest pain, overstimulation }\end{array}$ \\
\hline Benzphetamine & Appetite suppressant & $\begin{array}{l}\text { Short-term treatment } \\
\text { (up to } 12 \text { weeks) for adults }\end{array}$ & $\begin{array}{l}\text { Palpitation, tachycardia, elevation of blood pressure, } \\
\text { overstimulation, dizziness, insomnia, tremor, } \\
\text { sweating, headache, depression following withdrawal } \\
\text { of the drug, dryness of the mouth, unpleasant taste, } \\
\text { nausea, diarrhea }\end{array}$ \\
\hline Phendimetrazine & Appetite suppressant & $\begin{array}{l}\text { Short-term treatment } \\
\text { (up to } 12 \text { weeks) for adults }\end{array}$ & $\begin{array}{l}\text { Insomnia, hyperactivity, and blurred vision, increased } \\
\text { blood pressure and heart rates, overstimulation }\end{array}$ \\
\hline
\end{tabular}




\section{5-hydroxytryptamine (5HT) receptor and agonists}

Managing the natural inclination to eat is important for weightloss therapy. The hypothalamus appears to be a major center responsible for regulating hunger and food intake. ${ }^{19}$ Monoaminergic neurotransmitters, including dopamine, serotonin (5-hydroxytryptamine, 5-HT), and norepinephrine, mediate the signals for appropriate adjustments of food consumption. ${ }^{20}$ Stimulation of specific central serotonin receptors represents an effective pharmacological mechanism to suppress appetite. ${ }^{21}$ The 5-hydroxytryptamine $2\left(5 \mathrm{HT}_{2}\right)$ receptor, a member of the G-protein-coupled receptor family, is the target for a variety of centrally acting anti-obesity drugs. ${ }^{22-24}$ The $5 \mathrm{HT}_{2}$ receptor family members $5 \mathrm{HT}_{2 \mathrm{~A}}, 5 \mathrm{HT}_{2 \mathrm{~B}}$, and $5 \mathrm{HT}_{2 \mathrm{C}}$ distribute in different tissues and elicit distinctive biological activities. ${ }^{25} 5 \mathrm{HT}_{2 \mathrm{~A}}$ is located in the central nervous system (CNS, mainly the cortex and hippocampus), cardiac vessels, and heart valves. ${ }^{26}$ Most $5 \mathrm{HT}_{2 \mathrm{~B}} \mathrm{~s}$ are found in the cardiovascular system. ${ }^{27}$ Stimulation of $5 \mathrm{HT}_{2 \mathrm{~B}}$ may cause cardiomyopathy and endocardial fibrosis of cardiac valves. ${ }^{28}$ The $5 \mathrm{HT}_{2 \mathrm{C}}$ receptor shows high homology and similar pharmacological binding profiles to the $5 \mathrm{HT}_{2 \mathrm{~A}}$ receptor. ${ }^{29} 5 \mathrm{HT}_{2 \mathrm{C}}$ is almost exclusively located in the CNS and participates in the process of controlling caloric balance. Suppression of appetite is predominantly mediated by the $5-\mathrm{HT}_{2 \mathrm{C}}$ receptor, which is the target for anti-obesity treatment. ${ }^{30}$

Drugs targeting the 5-HT system have a long history in the management of obesity. The nonspecific $5 \mathrm{HT}_{2}$ agonists fenfluramine and dexfenfluramine were approved by the FDA for the treatment of obesity in 1973 and 1996, respectively. These weight-loss drugs became extremely popular for weight control and were commonly used in combination with phentermine. However, by 1997 both drugs were removed from the US market due to valvular heart diseases and pulmonary hypertension. These adverse effects are thought to occur through agonism of the $5-\mathrm{HT}_{2 \mathrm{~B}}$ receptor expressed on cardiac valvular interstitial cells and pulmonary artery smooth muscle cells. ${ }^{31}$ Given the specific activity of 5-HT $2 \mathrm{C}$ in appetite suppression, more selective agents that work on this receptor but with few or no effects on the $5 \mathrm{HT}_{2 \mathrm{~B}}$ or $5 \mathrm{HT}_{2 \mathrm{~A}}$ are being developed for obesity therapy.

\section{Lorcaserin: mode of action and pharmacokinetics}

Lorcaserin ((1R)-8-chloro-2,3,4,5-tetrahydro-1-methyl1H-3 benzazepine), developed by Arena Pharmaceuticals (San Diego, CA, USA), is a novel and selective $5-\mathrm{HT}_{2 \mathrm{C}}$ full agonist with $\sim 15$ - and $\sim 100$-fold higher affinity $\left(\mathrm{K}_{\mathrm{i}}=15 \pm 1 \mathrm{nM}\right)$ over those of $5-\mathrm{HT}_{2 \mathrm{~A}}$ and $5-\mathrm{HT}_{2 \mathrm{~B}}$ receptors. ${ }^{18,32}$ Lorcaserin differs from the earlier nonselective serotonin agonists fenfluramine and dexfenfluramine, in that it exerts minimal activity on 5- $\mathrm{HT}_{2 \mathrm{~A}}$ and $5-\mathrm{HT}_{2 \mathrm{~B}}$ receptors, which mediate the pathogenesis of serotonergic valvulopathy. ${ }^{18}$ Lorcaserin is indicated to promote weight loss in an obese population. Combined lorcaserin with a reduced-calorie diet and regular exercise is suggested for treating obese patients with a BMI of 30 or more and overweight patients with a BMI of 27 or higher and in the presence of at least one weight-related risk factor such as hypertension, dyslipidemia, cardiovascular disease, glucose intolerance, and sleep apnea. ${ }^{33}$ The recommended clinical dose of lorcaserin is $10 \mathrm{mg}$ twice daily, and the intended patient population is adults aged 18 years and older. Following oral administration (twice daily [b.i.d.]), more than $90 \%$ of lorcaserin can be rapidly absorbed. Time to reach maximum plasma concentration is approximately 1.5 to 2 hours, and its half-life $\left(\mathrm{T}_{1 / 2}\right)$ is about 11 hours. Approximately $70 \%$ of drugs are bound to plasma protein. The volume of distribution in the body is $\sim 252 \mathrm{~L}$ in a $92.5 \mathrm{~kg}$ subject. ${ }^{34}$ In both animals and human subjects, the brain is exposed to a much higher concentration of lorcaserin than that in plasma. The steady ratio of brain to plasma is 10 and 24 in the monkey and rat, respectively. ${ }^{18,35}$ Lorcaserin is mainly metabolized in the liver and excreted by the kidney. The major circulating metabolite is the sulfamate of lorcaserin (M1), and the major urinary metabolite is N-carbamoyl glucuronide (M5) ${ }^{34}$ Gender, race, age, and BMI have no significant effects on lorcaserin pharmacokinetics. In patients with renal impairment, lorcaserin and its metabolites increases by approximately 1.7- to 6-fold and cannot be removed from the circulation by hemodialysis. Hepatic dysfunction prolongs the plasma $\mathrm{T}_{1 / 2}$ of lorcaserin by about 5-9 hours. Lorcaserin is a mild to moderate inhibitor of CYP2D6; thus, the interaction potential with drugs such as dextromethorphan and desipramine should be noted during drug combinations. ${ }^{36,37}$

\section{Lorcaserin: clinical trials}

The clinical data comparing lorcaserin with other medications or in combination with other medications for the treatment of obesity are currently not available. Information can be obtained from one Phase II APD356-004 study and one Phase III clinical trial program (Behavioral Modification and Lorcaserin for Overweight and Obesity Management [BLOOM]) that evaluated more than 3000 patients treated with this drug for up to 2 years. ${ }^{33,38}$

APD356-004 trial (NCT00116740) was a randomized, doubled-blinded, placebo-controlled, parallel-arm study to 
evaluate the efficiency and safety of lorcaserin. ${ }^{38}$ This trial enrolled 469 obese patients aged between 18 and 65 years and with a BMI of 30-45. Patients with diabetes or other chronic diseases were excluded. Patients maintained their usual diet and exercise habits throughout the study. They were given placebo or lorcaserin at $10 \mathrm{mg}$ every day (q.d.), $15 \mathrm{mg}$ q.d., or $10 \mathrm{mg}$ b.i.d. for 12 weeks. The efficiency was evaluated by the weight changes of the endpoint compared with the baseline. The proportions of patients achieving more than $5 \%$ reduction from their initial body weight were $12.8 \%$, $19.5 \%$, and $31.2 \%$ in the $10 \mathrm{mg}$ q.d., $15 \mathrm{mg}$ q.d., and $10 \mathrm{mg}$ b.i.d. groups treated with lorcaserin, with average weight losses of $1.8 \mathrm{~kg}, 2.6 \mathrm{~kg}$, and $3.6 \mathrm{~kg}$, respectively. However, only $2.3 \%$ patients in the placebo group lost more than $5 \%$ body weight, and the mean weight loss was $0.3 \mathrm{~kg}$. In addition, BMI, total cholesterol, and waist circumference were decreased significantly in patients with lorcaserin $15 \mathrm{mg}$ q.d. and $10 \mathrm{mg}$ b.i.d. No significant valvular changes were detected by echocardiogram in patients treated with lorcaserin. The most common adverse effects were headache, nausea, and dizziness. ${ }^{38}$ Lorcaserin was identified as an effective drug for weight reduction in this 12-week study.

Long-term efficacy was assessed in one Phase III trial, BLOOM, which met the FDA Guidance for Industry Developing Products for Weight Management in February 2007. ${ }^{33}$ It was designed as a 104-week, double-blind, placebocontrolled clinical trial to assess the safety and efficacy of lorcaserin. A total of 3182 male and female patients between the ages of 18 and 65 years with a BMI of 30-45 with or without a comorbid condition, or a BMI of 27-29.9 with at least one comorbid condition, were included. Patients with pre-existing valvulopathy identified by echocardiograms were excluded. Diabetes mellitus was also one of the key exclusion criteria. They were randomly assigned to receive lorcaserin $(10 \mathrm{mg})$ or placebo b.i.d., in combination with a diet and exercise program. After 1 year, the proportion of patients achieving more than $5 \%$ weight loss was $47.5 \%$ and $20.3 \%$ in lorcaserin and placebo groups, respectively. The mean weight reduction was $5.8 \pm 0.2 \mathrm{~kg}$ in patients treated with lorcaserin $10 \mathrm{mg}$ b.i.d. and $2.2 \pm 0.1 \mathrm{~kg}$ in patients treated with placebo. At week 52, 22.6\% of patients in the lorcaserin group achieved more than 10\% weight loss from baseline, compared with $7.7 \%$ of patients treated with placebo.

At the end of year 1, patients receiving lorcaserin were randomized in a 2:1 ratio to either remain in the lorcaserin treatment group or to switch to placebo for the second year. Patients receiving placebo in year 1 remained on placebo in year 2 . The year 2 study was to assess the ability of lorcaserin to maintain body weight loss achieved during year 1. Among those who had weight loss of $5 \%$ or more, the weight loss was maintained in a greater proportion of patients who continued to receive lorcaserin in year 2 than in those who were reassigned to receive placebo $(67.9 \%$ versus $50.3 \%)$. The mean body weight among patients who received lorcaserin both years was lowest compared with patients who received placebo in both years or patients receiving lorcaserin in year 1 and placebo in year 2. By contrast, the patients switched from lorcaserin to placebo gained back the lost weight. Approximately the same body weight was found at year 2 as those who had received placebo for both years. Lorcaserin therapy resulted in clinically relevant improvements in almost all reported surrogate measures of type 2 diabetes and cardiovascular risk. It reduced the waist circumference as well as total cholesterol, low-density lipoprotein (LDL) cholesterol, and triglyceride. Moreover, high-sensitivity C-reactive protein, a marker of cardiovascular risk, was significantly decreased by about $1.2 \mathrm{mg} / \mathrm{L}$ compared with baseline in the lorcaserin group in year 1 , but not in the placebo group. The waist circumference and BMI, and the fasting glucose, insulin, total cholesterol, LDL cholesterol, and triglyceride levels, were decreased significantly in the lorcaserin-treated group.

Arena Pharmaceuticals conducted another Phase III trial, BLOOM-DM (Behavioral Modification and Lorcaserin for Overweight and Obesity Management in Diabetes Mellitus). The BLOOM-DM study evaluated 604 obese and overweight patients with type 2 diabetes. Patients were randomized to receive lorcaserin $10 \mathrm{mg}$ b.i.d., lorcaserin $10 \mathrm{mg}$ q.d., or placebo for 1 year. The briefing document for the FDA Advisory Committee Meeting (NDA 22-529) included the following information, which had not been peer reviewed. At week $52,37.5 \%$ of patients treated with lorcaserin $10 \mathrm{mg}$ b.i.d achieved at least a 5\% weight reduction, more than double the $16.1 \%$ of patients taking placebo. Mean weight loss was $4.7 \mathrm{~kg}$ in the lorcaserin group and $1.6 \mathrm{~kg}$ in the placebo group. A total of $16.3 \%$ of patients taking lorcaserin $10 \mathrm{mg}$ b.i.d achieved at least $10 \%$ weight loss compared with $4.4 \%$ of patients treated with placebo. Lorcaserin patients achieved statistically significant improvements relative to placebo in fasting glucose and glycated hemoglobin. Changes in fasting insulin, triglycerides, total cholesterol, high-density lipoprotein cholesterol, LDL cholesterol, and systolic and diastolic blood pressure were not significant.

\section{Lorcaserin: efficacy versus safety}

During the past several decades, most drugs for obesity treatment initially achieved regulatory approval, but when they 
reached the market they were subsequently withdrawn owing to serious adverse effects. ${ }^{39,40}$ For example, in 2007, the cannabinoid receptor antagonist rimonabant was withdrawn from the market because of an increased risk of depression, anxiety, and suicidal ideation. ${ }^{41}$ In January 2010, the European Medicine Agency Committee for Medicinal Products for Human Use recommended that the use of sibutramine (Meridia, Abbott Laboratories, North Chicago, IL, USA) be suspended based on the preliminary report from the 10,000patient, 6-year Sibutramine Cardiovascular Outcome Trial (SCOUT; ClinicalTrials.gov number, NCT00234832), which showed an increased risk of cardiovascular events with sibutramine as compared with placebo. ${ }^{42}$ In October 2010 , the FDA completed a review of the potential benefits and risks of Meridia and requested Abbott Laboratories to withdraw the drug from the market. Drugs targeting the serotonergic system have also had a history of being withdrawn. Fenfluramine and dexfenfluramine were removed from the market following reports of serious adverse events, including valvular heart disease, and an increased risk of pulmonary arterial hypertension. ${ }^{43-45}$

Compared with the lipase inhibitor orlistat, the weightloss efficacy of lorcaserin was slightly less. ${ }^{39}$ However, the safety and adverse event profiles of lorcaserin seem to be better. ${ }^{46,47}$ Treatment with this drug results in more beneficial effects on risk factors for type 2 diabetes and cardiovascular disease, including blood pressure, heart rate, and levels of LDL cholesterol. In the BLOOM trial, patients taking lorcaserin did not seem to have increased risk of valvulopathy, pulmonary hypertension, depression, or suicidal ideation. ${ }^{33}$ In year 1 of the BLOOM trial, the incidence rate of valvulopathy was $2.3 \%$ and $2.7 \%$ in the placebo and lorcaserin groups, respectively. In year 2 , the proportion of valvulopathy was $2.7 \%$ in patients treated with placebo and $2.6 \%$ in patients receiving lorcaserin in both years. Similar changes in mean pulmonary artery systolic pressure were observed in all study groups. However, it should be noted that the study was slightly underpowered regarding the primary safety endpoint of echocardiography. ${ }^{33}$ The most common adverse events in the lorcaserin group are upper respiratory infections, headache, dizziness, and nausea. The incidences of headache and dizziness were $18 \%$ and $8.2 \%$, respectively, in the lorcaserin group, compared with $11 \%$ and $3.8 \%$ in the placebo group in year 1 . During year 2 , the rates of headache were similar among all treatment groups. ${ }^{33}$ It was also reported that the headache and dizziness tended to be self-limited, mild, or moderate in severity. ${ }^{38}$ No apparent drug-related heart and artery dysfunction was observed during the
APD356-004 study. The patients with increased or decreased regurgitation did not differ between the placebo and lorcaserin groups. Additionally, in all groups, the frequencies of change in mean systolic pulmonary artery pressures more than $5 \mathrm{mmHg}$ were similar. ${ }^{38}$ In the BLOOM-DM trial, the most frequent adverse events included headache $(14.5 \%$ patients of the lorcaserin group versus $7.1 \%$ patients in the placebo group), upper respiratory infection (13.7\% versus $14.7 \%$ ), back pain (11.7\% versus $7.9 \%$ ), and nasopharyngitis (11.3\% versus 9.9\%). Hypoglycemia, including both asymptomatic low blood glucose measurements and symptomatic events, was $29.3 \%$ and $21.0 \%$ for lorcaserin $10 \mathrm{mg}$ b.i.d. and placebo groups, respectively. Valvulopathy was seen in $2.5 \%$ of lorcaserin (10 mg b.i.d.) patients and 1.9\% of placebo patients at week 24 , and $2.9 \%$ of lorcaserin (10 $\mathrm{mg}$ b.i.d.) patients and $0.5 \%$ of placebo patients at week 52 .

Five cases of serious adverse events were reported in the APD356-004 trial, including one kidney stone and pneumonia in the same patient receiving placebo treatment, one report of depression in a patient with a prior mood disorder history in the lorcaserin group, and a new-onset seizure on study day 71 in a patient taking lorcaserin $10 \mathrm{mg}$ b.i.d. ${ }^{38}$ In the BLOOM trial there was a similar frequency in serious adverse events among the three study groups. During year 1, the incidence of depression, depressive symptoms, or depressed mood was $2.5 \%$ in the lorcaserin group compared with $2.2 \%$ in the placebo group. In year 2 , the rates of depressive symptoms were $3.0 \%, 2.0 \%$, and $2.8 \%$ in patients given lorcaserin for 2 years, patients receiving placebo in both years, and patients given placebo in year 2 after 1 year's lorcaserin treatment. $^{33}$

Lorcaserin was generally well accepted. In the APD356004 trial, around the same number of patients completed the 12 -week study. The proportion of discontinued patients was $22 \%$ in placebo group and $21 \%$ in lorcaserin $10 \mathrm{mg}$ q.d., slightly less than $27 \%$ with lorcaserin $15 \mathrm{mg}$ q.d. and $10 \mathrm{mg}$ b.i.d. The most frequent reasons for study withdrawal were patient choice or being lost to follow-up. ${ }^{38}$ In the BLOOM study, only about $50 \%$ and $36 \%$ of the randomly assigned patients completed the first and second year of the study, respectively. The rate of completion at year 1 was $55.4 \%$ in the lorcaserin group and $45.1 \%$ in the placebo group, although this was similar to the rate in other large, long-term, randomized trials of obesity. ${ }^{33,47}$ The proportion of patients who discontinued the study because of adverse events was $7.1 \%$ and $6.7 \%$ in the lorcaserin and placebo groups, respectively. Headache and dizziness were major causes. The overall rate of completion of year 2 study was $72.6 \%$ of patients who 
completed year 1 study. The rates and reasons for discontinuation during year 2 were similar among the three groups.

In summary, more Phase III studies will be required to confirm these initial findings in larger populations of patients.

\section{Limitation and future prospective}

According to the FDA Guidance for Industry Developing Products for Weight Management, a product considered to be effective after 1 year of treatment should satisfy two efficiency endpoints. ${ }^{48}$ The primary efficacy endpoint refers to the difference in mean weight loss between the active product- and placebo-treated groups being at least 5\% and statistically significant. Moreover, the proportion of subjects who lose $\geq 5 \%$ of baseline body weight in the active product group is at least $35 \%$, or approximately double the proportion in the placebo-treated group, and the difference between groups is statistically significant. The second criterion of efficacy endpoint is that changes in the metabolic parameters, such as but not limited to blood pressure, lipids profile, glucose and insulin levels, and waist circumference, should be factored into efficiency assessment. In the BLOOM trial, although the weight loss observed in the lorcaserin-treated groups was associated with improvements of lipid profiles and a reduction in waist circumference and BMI, the percentage of patients who achieved equal to or more than a $5 \%$ reduction of body weight was not reaching the criteria to differentiate the active product and placebo groups. ${ }^{33}$

According to the announcement released by Arena Pharmaceuticals on September 16, 2010, the FDA Advisory Committee discussed the safety and efficacy of the lorcaserin trial. The drug was rejected by a vote of nine to five due to the concern that weight loss efficacy in nondiabetic overweight and obese subjects was marginal. In addition, animal studies suggested that lorcaserin may cause tumors in rats. There was uncertainty in the classification of mammary masses, an unresolved exposure-response relationship for lorcaserinemergent mammary adenocarcinoma, and an unidentified mode of action and unclear safety margin for lorcaserinemergent brain astrocytoma. In clinical studies, evidence could not be provided to alleviate concerns regarding the relevance of the tumor findings in rats. Recently, Arena Pharmaceuticals announced the findings from the 1-year BLOOMDM trial, demonstrating statistically significant weight loss in obese and overweight type 2 diabetic patients who met all three co-primary efficacy endpoints. However, a higher rate of valvulopathy was noted $(2.9 \%$ of patients with lorcaserin [10 mg b.i.d.] compared with $0.5 \%$ of patients with placebo at week 52). These data need to be peer reviewed and analyzed together with the previous clinical findings. At this stage, whether the concerns can be addressed and lorcaserin will be approved as a treatment for obesity remains unpredictable. Clearly, more basic research and clinical studies are required, especially to clarify the mechanism of tumor development in animals and to assess the uncertain risk in humans. Information regarding the distribution of lorcaserin in the CNS of both animals and human subjects would help to clarify the astrocytoma exposure margins. In addition, whether the weight loss effects of lorcaserin will be able to translate into clinical health benefits, especially the metabolic and cardiovascular outcomes, is a separate question.

\section{Disclosure}

The authors report no conflicts of interest in this work.

\section{References}

1. Haslam DW, James WP. Obesity. Lancet. 2005;366(9492):1197-1209.

2. York DA, Rossner S, Caterson I, et al. Prevention Conference VII: Obesity, a worldwide epidemic related to heart disease and stroke: Group I: worldwide demographics of obesity. Circulation. 2004; 110(18):e463-e470.

3. De Onis M, Blossner M, Borghi E. Global prevalence and trends of overweight and obesity among preschool children. Am J Clin Nutr. 2010;92(5):1257-1264.

4. Kumanyika SK, Obarzanek E, Stettler N, et al. Population-based prevention of obesity: the need for comprehensive promotion of healthful eating, physical activity, and energy balance: a scientific statement from American Heart Association Council on Epidemiology and Prevention, Interdisciplinary Committee for Prevention (formerly the expert panel on population and prevention science). Circulation. 2008;118(4):428-464.

5. Danaei G, Ding EL, Mozaffarian D, et al. The preventable causes of death in the United States: comparative risk assessment of dietary, lifestyle, and metabolic risk factors. PLoS Med. 2009;6(4):e1000058.

6. Kremers S, Reubsaet A, Martens M, et al. Systematic prevention of overweight and obesity in adults: a qualitative and quantitative literature analysis. Obes Rev. 2010;11(5):371-379.

7. Riebe D, Blissmer B, Greene G, et al. Long-term maintenance of exercise and healthy eating behaviors in overweight adults. Prev Med. 2005;40(6):769-778

8. Lindstrom J, Ilanne-Parikka P, Peltonen M, et al. Sustained reduction in the incidence of type 2 diabetes by lifestyle intervention: follow-up of the Finnish Diabetes Prevention Study. Lancet. 2006;368(9548): 1673-1679.

9. Wassertheil-Smoller S, Oberman A, Blaufox MD, Davis B, Langford H. The trial of antihypertensive interventions and management (TAIM) study. Final results with regard to blood pressure, cardiovascular risk, and quality of life. Am J Hypertens. 1992;5(1):37-44.

10. Lazo M, Solga SF, Horska A, et al. Effect of a 12-month intensive lifestyle intervention on hepatic steatosis in adults with type 2 diabetes. Diabetes Care. 2010;33(10):2156-2163.

11. Oza N, Eguchi Y, Mizuta T, et al. A pilot trial of body weight reduction for nonalcoholic fatty liver disease with a home-based lifestyle modification intervention delivered in collaboration with interdisciplinary medical staff. J Gastroenterol. 2009;44(12):1203-1208.

12. Flum DR, Salem L, Elrod JA, Dellinger EP, Cheadle A, Chan L. Early mortality among Medicare beneficiaries undergoing bariatric surgical procedures. JAMA. 2005;294(15):1903-1908.

13. Wolfe BM, Morton JM. Weighing in on bariatric surgery: procedure use, readmission rates, and mortality. JAMA. 2005;294(15):1960-1963. 
14. National Institutes of Health, National Heart, Lung, and Blood Institute, in cooperation with the National Institute of Diabetes and Digestive and Kidney Diseases. Clinical guidelines on the identification, evaluation, and treatment of overweight and obesity in adults: the evidence report. Obes Res. 1998;6 Suppl 2:S51-S209.

15. Bray GA, Greenway FL. Pharmacological treatment of the overweight patient. Pharmacol Rev. 2007;59(2):151-184.

16. Rubio MA, Gargallo M, Millan AI, Moreno B. Drugs in the treatment of obesity: sibutramine, orlistat and rimonabant. Public Health Nutr. 2007;10(10A):1200-1205.

17. Coutinho W. The first decade of sibutramine and orlistat: a reappraisal of their expanding roles in the treatment of obesity and associated conditions. Arq Bras Endocrinol Metabol. 2009;53(2):262-270.

18. Thomsen WJ, Grottick AJ, Menzaghi F, et al. Lorcaserin, a novel selective human 5-hydroxytryptamine2C agonist: in vitro and in vivo pharmacological characterization. J Pharmacol Exp Ther. 2008;325(2): 577-587.

19. Leibowitz SF, Weiss GF, Shor-Posner G. Hypothalamic serotonin: pharmacological, biochemical, and behavioral analyses of its feedingsuppressive action. Clin Neuropharmacol. 1988;11 Suppl 1:S51-S71.

20. Nelson DL, Gehlert DR. Central nervous system biogenic amine targets for control of appetite and energy expenditure. Endocrine. 2006;29(1): 49-60.

21. Bickerdike MJ. 5-HT2C receptor agonists as potential drugs for the treatment of obesity. Curr Top Med Chem. 2003;3(8):885-897.

22. Charney DS, Woods SW, Krystal JH, Heninger GR. Serotonin function and human anxiety disorders. Ann NY Acad Sci. 1990;600:558-573.

23. Lucki I, Kreider MS, Simansky KJ. Reduction of feeding behavior by the serotonin uptake inhibitor sertraline. Psychopharmacology (Berl). 1988;96(3):289-295.

24. Pascual J. Serotonin, serotonin receptors, serotonin receptor subtype agonists and pain. Pain. 1990;40(1):115-116.

25. Roth BL, Willins DL, Kristiansen K, Kroeze WK. 5-Hydroxytryptamine2family receptors (5-hydroxytryptamine2A, 5-hydroxytryptamine2B, 5-hydroxytryptamine2C): where structure meets function. Pharmacol Ther. 1998;79(3):231-257.

26. Hoyer D, Clarke DE, Fozard JR, et al. International Union of Pharmacology classification of receptors for 5-hydroxytryptamine (serotonin). Pharmacol Rev. 1994;46(2):157-203.

27. Kaumann AJ, Levy FO. 5-hydroxytryptamine receptors in the human cardiovascular system. Pharmacol Ther. 2006;111(3):674-706.

28. Xu J, Jian B, Chu R, et al. Serotonin mechanisms in heart valve disease II: the 5-HT2 receptor and its signaling pathway in aortic valve interstitial cells. Am J Pathol. 2002;161(6):2209-2218

29. Bos M, Jenck F, Martin JR, et al. Novel agonists of 5HT2C receptors. Synthesis and biological evaluation of substituted 2-(indol-1-yl)-1methylethylamines and 2-(indeno[1,2-b]pyrrol-1-yl)-1-methylethylamines. Improved therapeutics for obsessive compulsive disorder. J Med Chem. 1997;40(17):2762-2769.

30. Halford JC, Boyland EJ, Blundell JE, Kirkham TC, Harrold JA. Pharmacological management of appetite expression in obesity. Nat Rev Endocrinol. 2010;6(5):255-269.

31. Rothman RB, Baumann MH, Savage JE, et al. Evidence for possible involvement of 5-HT(2B) receptors in the cardiac valvulopathy associated with fenfluramine and other serotonergic medications. Circulation. 2000;102(23):2836-2841.
32. Smith BM, Smith JM, Tsai JH, et al. Discovery and structure-activity relationship of (1R)-8-chloro-2,3,4,5-tetrahydro-1-methyl-1H-3benzazepine (Lorcaserin), a selective serotonin 5-HT2C receptor agonist for the treatment of obesity. J Med Chem. 2008;51(2):305-313.

33. Smith SR, Weissman NJ, Anderson CM, et al. Multicenter, placebocontrolled trial of lorcaserin for weight management. $N$ Engl J Med. 2010;363(3):245-256.

34. Morgan M, Chen WC, Anderson C, Prosser W, Donahue D, Shanahan W. Pharmacokinetic properties, metabolism, and tolerability of lorcaserin in healthy volunteers. Annual Meeting of the Obesity Society; 2008 Oct 3-7; Phoenix, AZ, USA.

35. Chen WG, Xu J, Gwathney W, et al. Metabolism and disposition of lorcaserin, a novel selective serotonin 5-HT2c receptor agonist, in rats, mice, monkeys and humans. Drug Metab Rev. 2008;40:131.

36. Rodrigues AD, Roberts EM. The in vitro interaction of dexmedetomidine with human liver microsomal cytochrome P4502D6 (CYP2D6). Drug Metab Dispos. 1997;25(5):651-655.

37. Gueorguieva I, Jackson K, Wrighton SA, Sinha VP, Chien JY. Desipramine, substrate for CYP2D6 activity: population pharmacokinetic model and design elements of drug-drug interaction trials. $\mathrm{Br} J$ Clin Pharmacol. 2010;70(4):523-536.

38. Smith SR, Prosser WA, Donahue DJ, et al. Lorcaserin (APD356), a selective 5-HT2C agonist, reduces body weight in obese men and women. Obesity (Silver Spring). 2009;17(3):494-503.

39. Astrup A. Drug management of obesity - efficacy versus safety. NEngl J Med. 2010;363(3):288-290.

40. Viner RM, Hsia Y, Tomsic T, Wong IC. Efficacy and safety of antiobesity drugs in children and adolescents: systematic review and metaanalysis. Obes Rev. 2010;11(8):593-602.

41. Christensen R, Kristensen PK, Bartels EM, Bliddal H, Astrup A. Efficacy and safety of the weight-loss drug rimonabant: a meta-analysis of randomised trials. Lancet. 2007;370(9600):1706-1713.

42. Andersson C, Weeke P, Fosbol EL, et al. Acute effect of weight loss on levels of total bilirubin in obese, cardiovascular high-risk patients: an analysis from the lead-in period of the Sibutramine Cardiovascular Outcome trial. Metabolism. 2009;58(8):1109-1115.

43. Graham DJ, Green L. Further cases of valvular heart disease associated with fenfluramine-phentermine. N Engl J Med. 1997;337(9):635.

44. Rochefort GY, Lemaire MC, Eder V, et al. Dexfenfluramine does not worsen but moderates progression of chronic hypoxia-induced pulmonary hypertension. Eur J Pharmacol. 2006;550(1-3):149-154.

45. Souza R, Humbert M, Sztrymf B, et al. Pulmonary arterial hypertension associated with fenfluramine exposure: report of 109 cases. Eur Respir J. 2008;31(2):343-348.

46. Davidson MH, Hauptman J, DiGirolamo M, et al. Weight control and risk factor reduction in obese subjects treated for 2 years with orlistat a randomized controlled trial. JAMA. 1999;281(3):235-242.

47. Pi-Sunyer Fx, Aronne LJ, Heshmati HM, Devin J, Rosenstock J; RIO-North America Study Group. Effect of rimonabant, a cannabinoid-1 receptor blocker, on weight and cardiometabolic risk factors in overweight or obese patients: RIO-North America: a randomized controlled trial. JAMA. 2006;295(7):761-775.

48. Jones D. Novel pharmacotherapies for obesity poised to enter market. Nat Rev Drug Discov. 2009;8(11):833-834.

Drug Design, Development and Therapy

\section{Publish your work in this journal}

Drug Design, Development and Therapy is an international, peerreviewed open-access journal that spans the spectrum of drug design and development through to clinical applications. Clinical outcomes, patient safety, and programs for the development and effective, safe, and sustained use of medicines are a feature of the journal, which has

also been accepted for indexing on PubMed Central. The manuscript management system is completely online and includes a very quick and fair peer-review system, which is all easy to use. Visit http://www. dovepress.com/testimonials.php to read real quotes from published authors.

\section{Dovepress}

